\title{
Dissolution kinetics of manganese during nickel recovery from high iron grade laterite by acid leaching combined $\mathrm{NaOH}$-assisted mechanochemical technology
}

\author{
Seda ÇETINTASŢ ${ }^{1}$ (D), Deniz BİNGÖL ${ }^{1 *}$ (iD) \\ ${ }^{1}$ Kocaeli University, Department of Chemistry, Kocaeli / TURKEY
}

\begin{abstract}
This study investigates the effect of the process involving a combination of sodium-based reagent-assisted mechanochemical conversion ( $\mathrm{NaOH}-\mathrm{MC})$ and leaching, which was developed to provide highly efficient nickel recovery, on the amount of dissolved manganese during nickel recovery. For this purpose, firstly laterite was treated with $\mathrm{NaOH}$ as a reagent and then leaching performed in sulphuric acid medium. Response Surface Methodology (RSM) was successfully used as a statistical approach to determine the effect of parameters for both processes and to optimize processes conditions in terms of dissolved manganese. In optimum conditions determined as $0.5 \mathrm{M} \mathrm{H}_{2} \mathrm{SO}_{4}, 55 \mathrm{~mL} / \mathrm{g}$ liquid to solid ratio, $75^{\circ} \mathrm{C}$ and 30 min; dissolution amount of manganese from $\mathrm{NaOH}$-MC treated laterite was achieved as $97.54 \% \pm 1.06(\mathrm{~N}=2)$ with standard deviation. In addition, the dissolution behavior of manganese was defined by a control mechanism, a combination of chemical reaction and diffusion based on the shrinking core kinetic model. The activation energy of manganese dissolution was found as $35.42 \mathrm{~kJ} / \mathrm{mol}$. According to the results, the mechanochemistry contributed positively to the dissolution of manganese due to the increased leachability of laterite at low temperature and in a short time with low acid consumption.
\end{abstract}

\section{Article info \\ History:}

Received:04.03.2020

Accepted:02.06.2020

Keywords:

Atmospheric acid

leaching,

Laterite,

Manganese recovery,

Mechanochemical

conversion,

Response surface methodology.

\section{Introduction}

Manganese is a strategically important non-ferrous element used in a wide range of industrial production fields such as steel, ferromanganese, non-ferrous alloys, batteries, fertilizers, food additives, dyestuffs, and other chemicals. Manganese is produced by the electrolysis of manganese sulfate obtained from leaching in sulfuric acid of manganese ore, which is mainly in the form of $\mathrm{MnCO}_{3}$ and $\mathrm{MnO}_{2}$ in nature [1]. Manganese is found as an impurity in many hydrometallurgical processes. The manganesecontaining industrial waste effluents batteries, catalysts, steel scraps, and mud and slag from could be potentially important manganese sources [2]. The effluents downstream obtained after processing nickel laterite ore and zinc sphalerite ore are also potential manganese sources due to the contains a significant amount of manganese. On the other hand, it has been reported in many studies that manganese can be obtained from these low manganese-containing ores by using leaching with ferrous iron, sulfur dioxide, cuprous copper, hydrogen peroxide, nitrous acid, organic reductants, and bio- and electro-reductions [3]. In recent years, the increasing nickel demand in the world has created the need to develop new processes for the processing of nickel laterite ores. The applications of mechanochemical processes are innovative procedures that improve the efficiency of mineral processing due to the easy applicable, being economic and eco-friendly process compared to many technologies various technologies such as mechanical activation, alkali roasting, reduction process, microwave irradiation, and ultrasonic assistance. In recently, many researchers aim to obtain high efficiency by improving the leaching process in the field of hydrometallurgy by applying mechanochemical processes [4]. Mechanochemical processes that considerably affect the physical and chemical properties such as calcination temperature, melting point, dissolution rate, etc. of treated materials lead to favorable contributions to reaction kinetics as a result of this are useful technologies for improving the reactivity of minerals $[5,6]$. 
Determining the effects of the main processing parameters on the response is important to improve the performance of the method and thus make the method economically viable. In this study, RSM preferred for the development of processes is a multivariable optimization technique that includes main steps such as experimental matrix design, model development and validation, and optimization of parameters of processes. It is also possible to describe the complete influence of the parameters in the process combination of mathematical and statistical procedures with this approach. Moreover, RSM does not only evaluate the combined interactions between the independent variables but also providing more information in a short time, and economical [7].

In this study, the dissolution kinetics of manganese with acid leaching (AL) from high iron grade laterite ore which treated by $\mathrm{NaOH}$ assisted-mechanochemical process ( $\mathrm{NaOH}-\mathrm{MC})$ was investigated. Response Surface Methodology (RSM), as a statistical approach was used to improve the process by determining the significance of process parameters in both $\mathrm{AL}$ and $\mathrm{NaOH}$-MC, and also to determine the optimum processes conditions for achieving high removal efficiency. Furthermore, the kinetic data were evaluated by the shrinking core model (SCM) to identify the velocity mechanism affecting the manganese dissolution reaction (Figure 1).

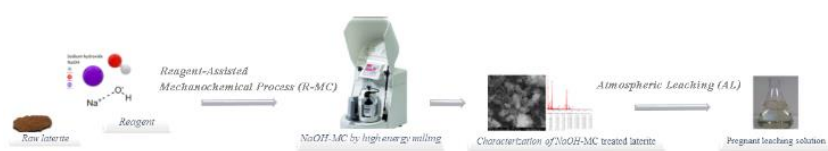

Figure 1. Flow chart for AL process following $\mathrm{NaOH}$-MC

\section{Materials and Methods}

\subsection{Laterite}

The laterite ore collected from Kayseri/Uzunpınar region of Turkey was used in this study. The ore samples were crushed to below $3.35 \mathrm{~mm}$ and ground to $-100 \mu \mathrm{m}$ to be used in experiments. The ore was characterized as a high-grade iron ore of limonitic type by X-ray diffraction (XRD) and multi-element analysis by Flame Atomic Absorption Spectrometer (FAAS) in our previous study. In our previous study, it was stated that laterite consists of main phases such as clinochlore $\left((\mathrm{Mg}, \mathrm{Fe})_{6}(\mathrm{Si}, \mathrm{Al})_{4} \mathrm{O}_{10}(\mathrm{OH})_{8}\right)$ and quartz $\left(\mathrm{SiO}_{2}\right)$, as well as hematite $\left(\mathrm{Fe}_{2} \mathrm{O}_{3}\right)$ and goethite $((\mathrm{Fe}, \mathrm{Ni}) \mathrm{O} . \mathrm{OH})$, and contains $32.1 \% \mathrm{Fe}, 1.40 \% \mathrm{Ni}, 0.56 \% \mathrm{Mn}, 3.2 \% \mathrm{Mg}$, $11.0 \% \mathrm{CaO}$ and $30.2 \% \mathrm{SiO}_{2}$ as wt\% [8].

In our previous study, the changes and transformations that occurred during mechanochemical conversion in ore mineralogy and the effect of adding $\mathrm{NaOH}$ as a reagent in mechanochemical conversion were demonstrated by analyses such as X-ray diffractometer (XRD, Rigaku Ultima-IV with a Cu-targeted X-ray tube by $2 \theta$ scanning), Fourier transform infrared spectroscopy (FTIR, Perkin Elmer 400/Bruker IFS 66/S), scanning electron microscopy (SEM, Quanta $400 \mathrm{~F}$ with $1.2 \mathrm{~nm}$ resolution) and simultaneously thermogravimetric analysis (TGA, Perkin Elmer/Pyris 1) and differential scanning calorimeter (DSC, Perkin Elmer/Diamond) [9]. The results of XRD analysis for $\mathrm{NaOH}$-MC treated laterite samples obtained from optimum mechanochemical conversion conditions indicated that mechanochemical processes caused amorphization, dehydration and crystal lattice defects as well as the reduction in particle size. In addition, TGA-DSC analysis showed that the dehydroxylation temperature of goethite to hematite had been found lower for $\mathrm{NaOH}$-MC treated samples than other MC treated samples. This situation was explained by the increasing agglomeration power due to the $\mathrm{NaOH}$ participation in the formation of structural water produced by $\mathrm{OH}^{-}$and $\mathrm{H}^{+}$ions which are broken down from the mineral structure (hydroxides, oxyhydroxides, clays, etc.) [9].

\subsection{Response surface methodology (RSM)}

All parameters of both $\mathrm{NaOH}$-MC and leaching processes affecting the leaching kinetics of manganese was determined by using RSM as the statistical design of experiment (DOE) technique. Central composite design (CCD) was employed to optimize the parameters of both $\mathrm{NaOH}-\mathrm{MC}$ and AL processes and to develop the quadratic mathematical models for processes.

CCD design matrix, widely used for modeling two or more factors, involves of a $2^{k}$ factorial (coded to the usual \pm 1 notation) augmented by $2 k$ axial points $( \pm \alpha$, $0,0),(0, \pm \alpha, 0),(0,0, \pm \alpha)$ and Co central points $(0,0$, $0)$. The number of experiments required for CCD is defined by the expression $N=2^{k}+2 k+$ Co $[9,10]$. The value of $\alpha$ for rotatability depends on the number of points in the factorial portion of the design which is given in Eq.1.

$\alpha=\left(N_{F}\right)^{1 / 4}$

where $N_{F}$ is the number of points in the cube portion of the design $\left(N_{F}=2^{k}, k\right.$ is the number of factors).

Experiments were carried out according to CCD experimental design, which aims to reduce the number of experiments and organize the experiments with 
various combinations of independent variables. Minitab statistical tool (Version 16) was used to design the experiment matrix for each process and all the detailed experimental data analysis, modeling and plotting graphics in the visualization of the model. Each obtained response from the design used to develop an empirical model that correlated the response to the parameters of the process using a second-degree polynomial equation given in Eq. 2:

$\mathrm{y}=\beta_{0}+\sum_{\mathrm{i}=1}^{\mathrm{k}} \beta_{\mathrm{i}} x_{\mathrm{i}}+\sum_{\mathrm{i}=1}^{\mathrm{k}} \beta_{\mathrm{ii}} x_{1}^{2}+\sum_{1 \leq \mathrm{i} \leq \mathrm{j}}^{\mathrm{k}} \beta_{\mathrm{ij}} x_{\mathrm{i}} x_{\mathrm{j}}+\varepsilon$

where; $x_{1}, x_{2}, \ldots, x_{\mathrm{k}}$ are input variables that are effective on response $(y) ; \beta_{0}$, is intercept, $\beta_{\mathrm{i}}(\mathrm{i}=1,2$, $\ldots . ., \mathrm{k})$, are coefficients of independent process variables, $\beta_{\mathrm{ii}}$ and $\beta_{\mathrm{ij}}(\mathrm{i}=1,2, \ldots, \mathrm{k} ; \mathrm{j}=1,2, \ldots, \mathrm{k})$ are interaction coefficients, $\varepsilon$ is random error [11].

The performance of the model is evaluated based on a statistical analysis of the obtained data by analysis of variance (ANOVA). While the determination coefficient $\left(R^{2}\right)$, adjusted determination coefficient $\left(R^{2}\right.$ (adj) ) and predicted determination coefficient $\left(R^{2}\right.$ (pred)) were used to evaluate the reliability of the model, the student $F$ test and probability value ( $P$ value) were used to evaluate the statistical significance of both the regression model and each term for the

Table 1. The experimental factors and levels in CCD matrix for $\mathrm{NaOH}$-MC process

\begin{tabular}{|c|c|c|c|c|c|c|c|c|c|}
\hline \multirow{2}{*}{\multicolumn{3}{|c|}{ Factors }} & \multirow{2}{*}{\multicolumn{2}{|c|}{ Symbol }} & \multicolumn{5}{|c|}{ Factor levels } \\
\hline & & & & & $-\alpha(-2.00)$ & -1 & 0 & +1 & $+\alpha(+2.00)$ \\
\hline \multicolumn{3}{|c|}{ rotational time $(\mathrm{RT}, \mathrm{min})$} & \multicolumn{2}{|l|}{$X_{1}$} & 30 & 83 & 135 & 188 & 240 \\
\hline \multicolumn{3}{|c|}{ ball to ore ratio (B/O ratio) } & \multicolumn{2}{|c|}{$X_{2}$} & 5 & 10 & 15 & 20 & 25 \\
\hline \multicolumn{3}{|c|}{ rotational speed (RS, rpm) } & \multicolumn{2}{|l|}{$X_{3}$} & 200 & 313 & 425 & 538 & 650 \\
\hline \multicolumn{3}{|c|}{ ore to reagent ratio $(\mathrm{O} / \mathrm{R}$ ratio) } & \multicolumn{2}{|l|}{$X_{4}$} & 5 & 10 & 15 & 20 & 25 \\
\hline \multirow[b]{2}{*}{ Run } & \multicolumn{4}{|c|}{ Coded levels of factors } & \multicolumn{5}{|c|}{ Actual levels of factors } \\
\hline & $X_{1}$ & $X_{2}$ & $X_{3}$ & $X_{4}$ & RT (min) & $\mathrm{B} / \mathrm{O}$ & & RS (rpm) & $\mathrm{O} / \mathrm{R}$ ratio \\
\hline 1 & -1 & -1 & -1 & -1 & 83 & & & 313 & 10 \\
\hline 2 & +1 & -1 & -1 & -1 & 188 & & & 313 & 10 \\
\hline 3 & -1 & +1 & -1 & -1 & 83 & & & 313 & 10 \\
\hline 4 & +1 & +1 & -1 & -1 & 188 & & & 313 & 10 \\
\hline 5 & -1 & -1 & +1 & -1 & 83 & & & 538 & 10 \\
\hline 6 & +1 & -1 & +1 & -1 & 188 & & & 538 & 10 \\
\hline 7 & -1 & +1 & +1 & -1 & 83 & & & 538 & 10 \\
\hline 8 & +1 & +1 & +1 & -1 & 188 & & & 538 & 10 \\
\hline 9 & -1 & -1 & -1 & +1 & 83 & & & 313 & 20 \\
\hline 10 & +1 & -1 & -1 & +1 & 188 & & & 313 & 20 \\
\hline 11 & -1 & +1 & -1 & +1 & 83 & & & 313 & 20 \\
\hline 12 & +1 & +1 & -1 & +1 & 188 & & & 313 & 20 \\
\hline 13 & -1 & -1 & +1 & +1 & 83 & & & 538 & 20 \\
\hline 14 & +1 & -1 & +1 & +1 & 188 & & & 538 & 20 \\
\hline 15 & -1 & +1 & +1 & +1 & 83 & & & 538 & 20 \\
\hline 16 & +1 & +1 & +1 & +1 & 188 & & & 538 & 20 \\
\hline 17 & -2.00 & 0 & 0 & 0 & 30 & & & 425 & 15 \\
\hline 18 & +2.00 & 0 & 0 & 0 & 240 & & & 425 & 15 \\
\hline 19 & 0 & -2.00 & 0 & 0 & 135 & & & 425 & 15 \\
\hline 20 & 0 & +2.00 & 0 & 0 & 135 & & & 425 & 15 \\
\hline 21 & 0 & 0 & -2.00 & 0 & 135 & & & 200 & 15 \\
\hline 22 & 0 & 0 & +2.00 & 0 & 135 & & & 650 & 15 \\
\hline 23 & 0 & 0 & 0 & -2.00 & 135 & & & 425 & 5 \\
\hline 24 & 0 & 0 & 0 & +2.00 & 135 & & & 425 & 25 \\
\hline $25-31$ & 0 & 0 & 0 & 0 & 135 & & & 425 & 15 \\
\hline
\end{tabular}

model. Then later, the selection of the most suitable factor levels for process optimization was carried out by Derringer's desirability approach [9].

\section{3. $\mathrm{NaOH}$-assisted mechanochemical conversion}

$\mathrm{NaOH}$-MC process was performed in the planetary ball mill (Pulverisette 6 model, Fritsch, Germany) using a $250 \mathrm{~mL}$ zirconium oxide grinding jar and $10 \mathrm{~mm}-$ diameter zirconium oxide balls. The sodium hydroxide used as a reagent was of analytical grade from MERCK (pellets EMPLURA®, MW: $40.00 \mathrm{~g} / \mathrm{mol}$ ). For $\mathrm{NaOH}$ MC experiments, the design matrix consisted of total 31 experimental runs which include 16 factorial points, 8 axial points and 7 replicates at the center points (Table 1). The $\alpha$ value was 2.00 (rotatable). The amount of manganese taken into solution was the experimental response. $\mathrm{NaOH}-\mathrm{MC}$ treated laterite samples obtained from each experiments were subjected to AL under constant conditions (initial acid concentration $(\mathrm{Co})=0.5 \mathrm{M}$, liquid to solid ratio $(\mathrm{L} / \mathrm{S})$ $=100 \mathrm{~mL} / \mathrm{g}$, at room temperature, for leaching time $(\mathrm{t})$ $=30 \mathrm{~min}$ ) 


\subsection{Atmospheric leaching}

The manganese dissolution behavior of $\mathrm{NaOH}-\mathrm{MC}$ treated laterite samples was investigated by atmospheric leaching in sulphuric acid medium $\left(\mathrm{H}_{2} \mathrm{SO}_{4}, 95-98 \%\right.$ (w/w) extra pure, Merck). CCD was performed to enhance the dissolution of manganese by optimizing process conditions for leaching of $\mathrm{NaOH}$ $\mathrm{MC}$ treated laterite. The statistical experimental design produced by CCD was applied to study the combined effect of parameters as initial acid concentration, liquid to solid ratio and temperature on manganese dissolution. The experiments were performed in accordance with the full factorial CCD matrix included eight factorial points $( \pm 1)$, six axial points $(\alpha= \pm 1.682)$ and six central points (0) (Table 2). The experimental leaching procedure was similar to our previous study [12]. The experiments were carried out in a temperature controlled water bath by mechanically mixing ore and acid solution in a $600 \mathrm{~mL}$ beaker with a Teflon mixer at $200 \mathrm{rpm}$. The reflux system was connected to prevent evaporation at high temperatures. After the leaching time $(30 \mathrm{~min})$, the leachate was filtered using a syringe filter $(0.45 \mu \mathrm{m})$ and analyzed for Mn(II) using FAAS (PerkinElmer/AAnalyst 800).

Table 2. The experimental factors and levels in CCD matrix for the leaching process

\begin{tabular}{|c|c|c|c|c|c|c|c|c|}
\hline \multirow{2}{*}{ Factors } & & \multirow{2}{*}{\multicolumn{2}{|c|}{ Symbol }} & \multicolumn{5}{|c|}{ Factor levels } \\
\hline & & & & $-\alpha(-1.682)$ & -1 & 0 & +1 & $+\alpha(+1.682)$ \\
\hline \multirow{3}{*}{\multicolumn{2}{|c|}{$\begin{array}{l}\text { acid concentration }(\mathrm{Co}, \mathrm{M}) \\
\text { liquid to solid ratio }(\mathrm{L} / \mathrm{S}, \mathrm{mL} / \mathrm{g}) \\
\text { temperature }\left(\mathrm{T},{ }^{\circ} \mathrm{C}\right)\end{array}$}} & \multicolumn{2}{|c|}{$X_{1}$} & 0.5 & 0.8 & 1.25 & 1.70 & 2.00 \\
\hline & & \multicolumn{2}{|c|}{$X_{2}$} & 10 & 28 & 55 & 82 & 100 \\
\hline & & \multicolumn{2}{|c|}{$X_{3}$} & 25 & 39 & 60 & 81 & 95 \\
\hline \multirow[b]{2}{*}{ Run } & \multicolumn{3}{|c|}{ Coded levels } & \multicolumn{5}{|c|}{ Actual levels } \\
\hline & $X_{1}$ & $X_{2}$ & $X_{3}$ & \multicolumn{5}{|c|}{$\mathrm{L} / \mathrm{S}$ ratio $(\mathrm{mL} / \mathrm{g})$} \\
\hline 1 & $\begin{array}{ll}-1 \\
\end{array}$ & -1 & $\begin{array}{ll}-1 \\
\end{array}$ & \multicolumn{2}{|l|}{0.80} & \multicolumn{2}{|c|}{28} & 39 \\
\hline 2 & +1 & -1 & -1 & \multicolumn{2}{|l|}{1.70} & \multicolumn{2}{|c|}{28} & 39 \\
\hline 3 & -1 & +1 & -1 & \multicolumn{2}{|l|}{0.80} & \multicolumn{2}{|c|}{82} & 39 \\
\hline 4 & +1 & +1 & -1 & \multicolumn{2}{|l|}{1.70} & \multicolumn{2}{|c|}{82} & 39 \\
\hline 5 & -1 & -1 & +1 & \multicolumn{2}{|l|}{0.80} & \multicolumn{2}{|c|}{28} & 81 \\
\hline 6 & +1 & -1 & +1 & \multicolumn{2}{|l|}{1.70} & \multicolumn{2}{|c|}{28} & 81 \\
\hline 7 & -1 & +1 & +1 & \multicolumn{2}{|l|}{0.80} & \multicolumn{2}{|c|}{82} & 81 \\
\hline 8 & +1 & +1 & +1 & \multicolumn{2}{|l|}{1.70} & \multicolumn{2}{|c|}{82} & 81 \\
\hline 9 & -1.68 & 0 & 0 & \multicolumn{2}{|l|}{0.50} & \multicolumn{2}{|c|}{55} & 60 \\
\hline 10 & +1.68 & 0 & 0 & \multicolumn{2}{|l|}{2.00} & \multicolumn{2}{|c|}{55} & 60 \\
\hline 11 & 0 & -1.68 & 0 & \multicolumn{2}{|l|}{1.25} & \multicolumn{2}{|c|}{10} & 60 \\
\hline 12 & 0 & +1.68 & 0 & \multicolumn{2}{|l|}{1.25} & & 00 & 60 \\
\hline 13 & 0 & 0 & -1.68 & 1.25 & & & 5 & 25 \\
\hline 14 & 0 & 0 & +1.68 & 1.25 & & & 5 & 95 \\
\hline $15-20$ & 0 & 0 & 0 & 1.25 & & & 5 & 60 \\
\hline
\end{tabular}

\subsection{Kinetic evaluation of leaching process}

The shrinking core model (SCM) has been applying for determining the rate-limiting mechanism of the laterite leaching process. This model assumes that the solid particle that maintains the bulk size gradually shrinks during the reaction that leads to the formation of a porous layer on the surface of the unreacted core [13]. SCM considers that the reaction mechanism of consists of three rate-determining steps as film diffusion control, ash layer diffusion control, and surface chemical reaction control [14]. The following equations of the shrinking core model are used to describe the dissolution kinetics:

If the reaction is controlled by a chemical reaction on the surface,

$$
1-(1-\alpha)^{1 / 3}=k_{s} \cdot \mathrm{t}
$$

If the reaction is controlled by diffusion through a liquid film or through a liquid-solid layer,

$$
\begin{aligned}
& 1-(1-\alpha)^{2 / 3}=k_{\mathrm{f}} \mathrm{t} \\
& 1-2 / 3 \alpha-(1-\alpha)^{2 / 3}=k_{\mathrm{d}} \mathrm{t}
\end{aligned}
$$

If the reaction is controlled by a combination of both chemical and diffusion,

$1-2(1-\alpha)^{1 / 3}+(1-\alpha)^{2 / 3}=k_{\mathrm{m}} \cdot \mathrm{t}$

where $\alpha$ is the fraction of reacted, $\mathrm{t}$ is the reaction time, and $k_{\mathrm{s}}, k_{\mathrm{f}}, k_{\mathrm{dif}}$ and $k_{\mathrm{m}}$ are the rate constants.

Evaluations regarding the explanation of kinetic data by SCM models were made according to the correlation coefficients of fitting curves obtained by applying the data to model equations. The reaction rate 
constants predicted by the models are determined from the slopes of curves ( $k_{\mathrm{s}}, k_{\mathrm{f}}, k_{\text {dif }}$ and $k_{\mathrm{m}}$ ) [14].

The activation energy $(E a, \mathrm{~kJ} / \mathrm{mol})$ for the reaction is determined based on Arrhenius relation (Eq. 7) with using the rate constant. The fact that the $E$ a is lower than $20 \mathrm{~kJ} / \mathrm{mol}$ defines diffusion-controlled processes while $E$ a is higher than $40 \mathrm{~kJ} / \mathrm{mol}$ for chemical reaction controlled processes [13].

In $k=$ In $\mathrm{A}-\frac{E \mathrm{a}}{\mathrm{RT}}$

where $\mathrm{k}$ is the rate constant $(1 / \mathrm{min}), \mathrm{A}$ is the frequency factor $(1 / \mathrm{min}), \mathrm{R}(8.314 \mathrm{~J} / \mathrm{K} \mathrm{mol})$ is the ideal gas constant and $\mathrm{T}(\mathrm{K})$ is temperature. Ea is calculated from the slope of the Arrhenius plot (In $k$ vs $1 / T$ ).

\section{Results and Discussion}

\subsection{Optimization of $\mathrm{NaOH}-\mathrm{MC}$ conditions}

ANOVA results for $\mathrm{NaOH}-\mathrm{MC}$ based on manganese recovery with AL were summarized in Table 3 . The effects of terms such as $X_{4} * X_{4}$ ( $P$-value: 0.273$)$ of square interaction and $X_{1} * X_{2}$ ( $P$-value: 0.183$), X_{1} * X_{4}$ ( $P$-value: 0.050$), X_{2} * X_{4}(P$-value: 0.250$)$ and $X_{3} * X_{4}(P$ value: 0.246$)$ of 2 -Way interaction, were found not be statistically significant on the amount of manganese taken into solution due to higher $P$-values than 0.05 .

Table 3. ANOVA results based on manganese recovery for $\mathrm{NaOH}-\mathrm{MC}$ with AL

\begin{tabular}{|c|c|c|c|c|c|c|}
\hline Source & $\mathrm{DF}$ & Adj SS & Adj MS & $F$-Value & $P$-Value & VIF \\
\hline Model & 14 & 13051.5 & 932.25 & 31.89 & 0.000 & \\
\hline Linear & 4 & 8533.4 & 2133.34 & 72.97 & 0.000 & \\
\hline$X_{1}$ : rotational time $(\mathrm{RT}, \mathrm{min})$ & 1 & 340.7 & 340.69 & 11.65 & 0.001 & 1.00 \\
\hline$X_{2}$ : ball/ore ratio (B/O ratio) & 1 & 2207.0 & 2207.03 & 75.49 & 0.000 & 1.00 \\
\hline$X_{3}:$ rotational speed $(\mathrm{RS}, \mathrm{rpm})$ & 1 & 5449.0 & 5448.97 & 186.37 & 0.000 & 1.00 \\
\hline$X_{4:}$ ore/reagent ratio $(\mathrm{O} / \mathrm{R}$ ratio $)$ & 1 & 536.7 & 536.67 & 18.36 & 0.000 & 1.00 \\
\hline Square & 4 & 2385.1 & 596.26 & 20.39 & 0.000 & \\
\hline$X_{1} * X_{1}$ & 1 & 626.1 & 626.13 & 21.42 & 0.000 & 1.03 \\
\hline$X_{2} * X_{2}$ & 1 & 719.2 & 719.25 & 24.60 & 0.000 & 1.03 \\
\hline$X_{3} * X_{3}$ & 1 & 1502.6 & 1502.55 & 51.39 & 0.000 & 1.03 \\
\hline$X_{4} * X_{4}$ & 1 & 36.0 & 35.98 & 1.23 & 0.273 & 1.03 \\
\hline 2-Way Interaction & 6 & 2133.1 & 355.52 & 12.16 & 0.000 & \\
\hline$X_{1} * X_{2}$ & 1 & 53.5 & 53.46 & 1.83 & 0.183 & 1.00 \\
\hline$X_{1} * X_{3}$ & 1 & 486.1 & 486.10 & 16.63 & 0.000 & 1.00 \\
\hline$X_{1} * X_{4}$ & 1 & 118.1 & 118.12 & 4.04 & 0.050 & 1.00 \\
\hline$X_{2} * X_{3}$ & 1 & 1395.5 & 1395.50 & 47.73 & 0.000 & 1.00 \\
\hline$X_{2} * X_{4}$ & 1 & 39.6 & 39.61 & 1.35 & 0.250 & 1.00 \\
\hline$X_{3} * X_{4}$ & 1 & 40.3 & 40.32 & 1.38 & 0.246 & 1.00 \\
\hline Error & 47 & 1374.2 & 29.24 & & & \\
\hline Lack-of-Fit & 10 & 1233.8 & 123.38 & 32.53 & 0.000 & \\
\hline Pure Error & 37 & 140.3 & 3.79 & & & \\
\hline Total & 61 & 14425.7 & & & & \\
\hline Model Summary $\quad: S=5.41$ & $\mathrm{R}^{2}=90.47 \%$ & $\mathrm{R}^{2}(\mathrm{a}$ & $64 \%$ & $\mathrm{R}^{2}($ pred $)=81.19 \%$ & & \\
\hline Reduced Model Summary: $\mathrm{S}=1.52$ & $\mathrm{R}^{2}=99.11 \%$ & $\mathrm{R}^{2}(\mathrm{a}$ & $92 \%$ & $\mathrm{R}^{2}($ pred $)=98.60 \%$ & & \\
\hline
\end{tabular}

The surface and contour plots presented in Figures 2 and 3 , respectively, show the effects of factors on the $\mathrm{NaOH}$-MC process based on the amount of manganese taken into solution by AL. It was seen that manganese dissolution was almost unchanged with increasing $O / R$ ratio for changing levels of $\mathrm{B} / \mathrm{O}$ ratio and $\mathrm{RS}$. The dissolution rate of manganese increased with increasing $\mathrm{B} / \mathrm{O}$ ratio and $\mathrm{RS}$ but it remained stable after certain levels of factors $(\mathrm{B} / \mathrm{O}$ ratio $=16$ and $\mathrm{RS}=425$ $\mathrm{rpm})$. While increasing the $\mathrm{B} / \mathrm{O}$ ratio causes a continuous increase in manganese dissolution, it was determined that the model predicts high $\mathrm{B} / \mathrm{O}$ ratios for the best recovery. Because, the increase in $\mathrm{B} / \mathrm{O}$ ratio during the mechanochemical process leads to cause amorphization and structural disordering in laterite, as well as the decrease in particle size [15]. In addition, it indicated that the dissolution rate of manganese increased by increased rotational time up to $135 \mathrm{~min}$, but it decreased by increased rotational time above 135 $\min$. 

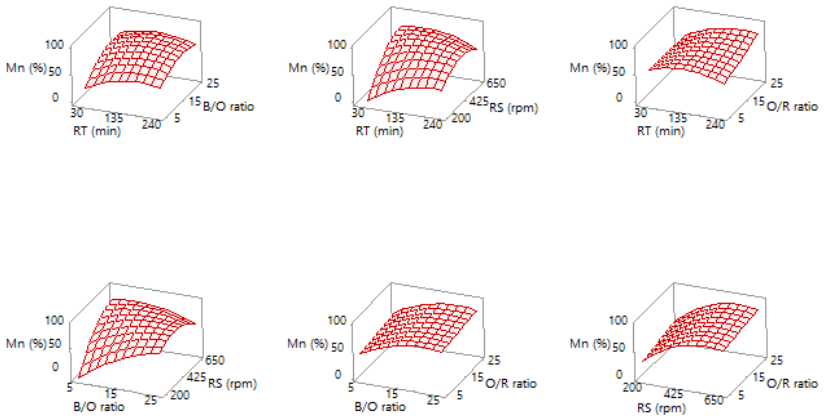

$\operatorname{Mn}(\%)=78.26+2.664 X_{1}+6.781 X_{2}+10.655 X_{3}+3.344 X_{4}$

$-3.224 X_{1}^{2}-3.462 X_{2}^{2}-5.041 X_{3}^{2}-1.293 X_{1} * X_{2}$

$-3.897 X_{1} * X_{3}+1.921 X_{1} * X_{4}-6.604 X_{2} * X_{3}$

Figure 2. Response surface plots for $\mathrm{NaOH}$-MC based on manganese recovery with AL. (Hold values: $\mathrm{RT}=135 \mathrm{~min}$, $\mathrm{B} / \mathrm{O}$ ratio $=15, \mathrm{RS}=425 \mathrm{rpm}$ and $\mathrm{O} / \mathrm{R}$ ratio $=15)$

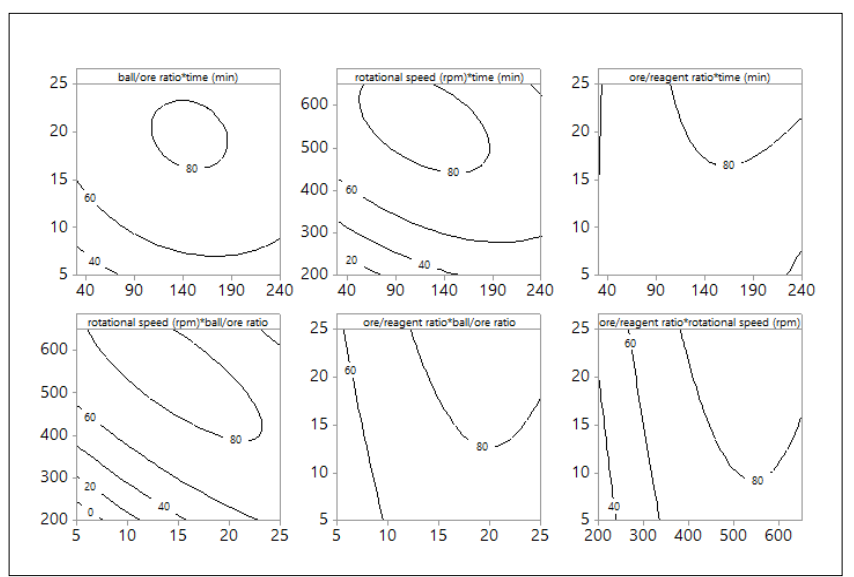

Figure 3. Contour plots for $\mathrm{NaOH}$-MC based on manganese recovery with AL. (Hold values: $\mathrm{RT}=135 \mathrm{~min}, \mathrm{~B} / \mathrm{O}$ ratio $=$ $15, \mathrm{RS}=425 \mathrm{rpm}$ and $\mathrm{O} / \mathrm{R}$ ratio $=15$ )
The optimum conditions determined for highefficiency nickel recovery considering the amount of nickel dissolution were $\mathrm{RT}=135 \mathrm{~min}, \mathrm{~B} / \mathrm{O}$ ratio $=15$, $\mathrm{RS}=425 \mathrm{rpm}$ and $\mathrm{O} / \mathrm{R}$ ratio $=18$ for $\mathrm{NaOH}-\mathrm{MC}$ process. In these conditions, the predicted and the experimental manganese recoveries with standard deviations were found as $80.27 \% \pm 1.52(\mathrm{~N}=2)$ and $82.30 \% \pm 0.93(\mathrm{~N}=2)$, respectively.

\subsection{Optimization of AL conditions}

ANOVA results for AL following $\mathrm{NaOH}$-MC were evaluated based on the amount of manganese taken into solution (see Table 4). The terms which have statistically insignificant effects on the amount of manganese taken into solution were neglected in the model due to high $P$-values. The reduced model equation was obtained by gradually neglecting the terms ( $P$-value: 0.697 for $\left.X_{1} * X_{1}\right)$. The model equation indicated that temperature ( $F$-value: 101.51 and $P$ value: 0.000 ) was the most effective factor for the amount of manganese taken into solution.

Table 4. ANOVA results for manganese recovery with AL following $\mathrm{NaOH}$-MC

\begin{tabular}{|c|c|c|c|c|c|c|c|}
\hline Source & & DF & Adj SS & Adj MS & $F$-Value & $P$-Value & VIF \\
\hline Model & & 9 & 2841.77 & 315.75 & 21.63 & 0.000 & \\
\hline Linear & & 3 & 1803.10 & 601.03 & 41.17 & 0.000 & \\
\hline 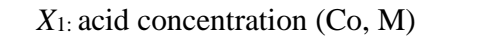 & & 1 & 93.27 & 93.27 & 6.39 & 0.017 & 1.00 \\
\hline$X_{2:}$ liquid to Solid ratio $(\mathrm{L} / \mathrm{S}, \mathrm{mL} / \mathrm{g})$ & & 1 & 228.07 & 228.07 & 15.62 & 0.000 & 1.00 \\
\hline$X_{3:}$ temperature $\left(\mathrm{T},{ }^{\circ} \mathrm{C}\right)$ & & 1 & 1481.76 & 1481.76 & 101.51 & 0.000 & 1.00 \\
\hline Square & & 3 & 880.08 & 293.36 & 20.10 & 0.000 & \\
\hline$X_{1} * X_{1}$ & & 1 & 2.26 & 2.26 & 0.15 & 0.697 & 1.02 \\
\hline$X_{2} * X_{2}$ & & 1 & 830.54 & 830.54 & 56.90 & 0.000 & 1.02 \\
\hline$X_{3} * X_{3}$ & & 1 & 91.80 & 91.80 & 6.29 & 0.018 & 1.02 \\
\hline 2-Way Interaction & & 3 & 158.59 & 52.86 & 3.62 & 0.024 & \\
\hline$X_{1} * X_{2}$ & & 1 & 22.29 & 22.29 & 1.53 & 0.226 & \\
\hline$X_{1} * X_{3}$ & & 1 & 15.74 & 15.74 & 1.08 & 0.307 & \\
\hline$X_{2} * X_{3}$ & & 1 & 120.56 & 120.56 & 8.26 & 0.007 & \\
\hline Error & & 30 & 437.92 & 14.60 & & & \\
\hline Lack-of-Fit & & 5 & 354.80 & 70.96 & 21.34 & 0.000 & \\
\hline Pure Error & & 25 & 83.12 & 3.32 & & & \\
\hline Total & & 39 & 3279.68 & & & & \\
\hline Model Summary & $\mathrm{R}^{2}=86.65 \%$ & & $=82.64 \%$ & $\mathrm{R}^{2}$ (pred & $2.96 \%$ & & \\
\hline Reduced Model Summary: $\mathrm{S}=0.27$ & $\mathrm{R}^{2}=99.92 \%$ & & $=99.90 \%$ & $\mathrm{R}^{2}$ (pred & $.88 \%$ & & \\
\hline
\end{tabular}


The surface and contour plots for manganese recovery with AL following $\mathrm{NaOH}$-MC were given in Figures 4 and 5, respectively. Figure 4a clearly showed that the leaching rate of manganese increases initially with increases of the L/S ratio, then the leaching rate decreases with increasing the L/S ratio. The optimum manganese recovery was achieved with an efficiency of over $95 \%$ at the $\mathrm{L} / \mathrm{S}$ of $55 \mathrm{~mL} / \mathrm{g}$.

In addition, it was seen that the effect of Co was insignificant, the leaching rate of manganese remained almost stable with increasing Co. While the difference in obtained manganese dissolution for the levels of Co ranging from 0.50 to $2.00 \mathrm{M}$ at constant $\mathrm{L} / \mathrm{S}$ ratio (55 $\mathrm{mL} / \mathrm{g}$ ) was only $3 \%$ for the temperature was $70{ }^{\circ} \mathrm{C}$ and above, it was $15 \%$ for the temperature below $70^{\circ} \mathrm{C}$. Figures $4 \mathrm{~b}$ and $4 \mathrm{c}$ indicated that the leaching of manganese increased with increasing temperature. While the temperature was changing from 25 to $95^{\circ} \mathrm{C}$, the amount of manganese taken into solution increased from $53.02 \%$ to $87.72 \%$ for $10 \mathrm{~mL} / \mathrm{g}$, increased from $84.95 \%$ to $88.59 \%$ for $\mathrm{L} / \mathrm{S}$ ratio of $100 \mathrm{~mL} / \mathrm{g}$ at constant Co $(0.50 \mathrm{M})$. The optimum leaching conditions following $\mathrm{NaOH}$-MC were determined as $\mathrm{Co}=0.50 \mathrm{M}, \mathrm{L} / \mathrm{S}$ ratio $=55 \mathrm{~mL} / \mathrm{g}$ and $\mathrm{T}=75^{\circ} \mathrm{C}$. Under these conditions, the predicted and the experimental manganese recoveries with standard deviations were found as $98.03 \% \pm 0.27(\mathrm{~N}=2)$ and $97.54 \% \pm 1.06(\mathrm{~N}$ $=2$ ), respectively.

(a)

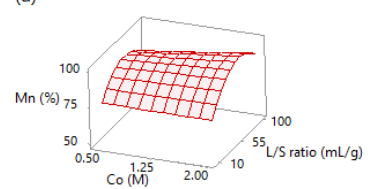

(b)

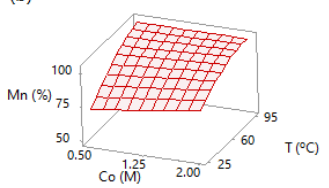

(c)

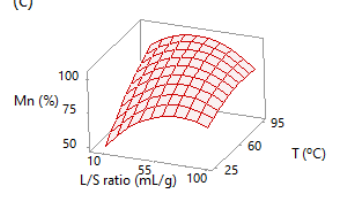

$\operatorname{Mn}(\%)=95.53+1.848 X_{1}+2.890 X_{2}+7.365 X_{3}-5.340 X_{2}^{2}$ $-1.757 X_{3}^{2}+1.180 X_{1} * X_{2}-0.992 X_{1} * X_{3}-2.745 X_{2} * X_{3}$

Figure 4. Response surface plots for manganese recovery with $\mathrm{AL}$ following $\mathrm{NaOH}-\mathrm{MC}$ (Hold values: $\mathrm{Co}=1.25 \mathrm{M}$ $\mathrm{H}_{2} \mathrm{SO}_{4}, \mathrm{~L} / \mathrm{S}$ ratio $=55 \mathrm{~mL} / \mathrm{g}$ and $\left.\mathrm{T}=60^{\circ} \mathrm{C}\right)$

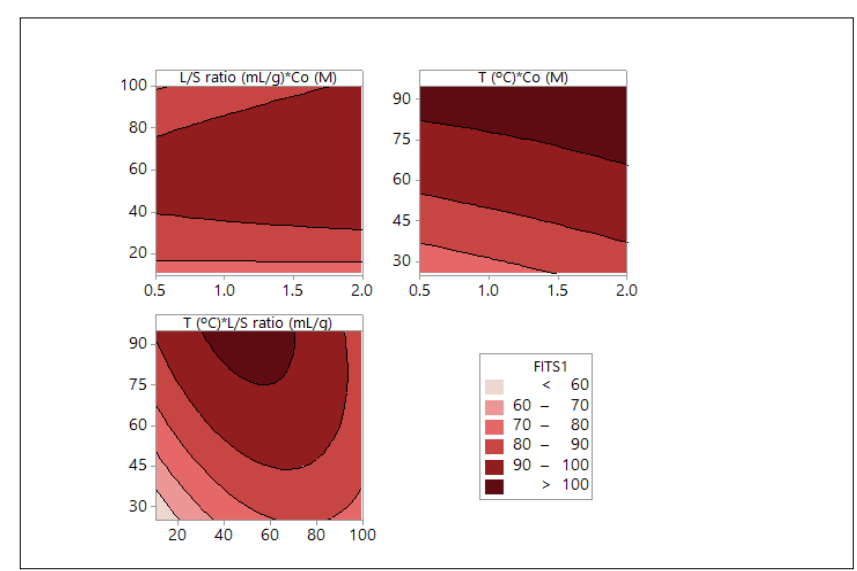

Figure 5. Contour plots for manganese recovery with $\mathrm{AL}$ following $\mathrm{NaOH}$-MC (Hold values: $\mathrm{Co}=1.25 \mathrm{M} \mathrm{H}_{2} \mathrm{SO}_{4}$, $\mathrm{L} / \mathrm{S}$ ratio $=55 \mathrm{~mL} / \mathrm{g}$ and $\mathrm{T}=60^{\circ} \mathrm{C}$ )

\subsection{Kinetic analysis of leaching}

The rate-limiting control mechanism of manganese dissolution reactions was investigated based on SCM assumptions. The graphs obtained by fitting the data to SCM model equations were also given in Figure 6. Significant model constants calculated using these graphs were summarized in Table 5.

The Eq. 4 related to the combination of chemical reaction and diffusion mechanisms had the best correlation with experimental data. The model with high $R^{2}$ value indicates that the manganese dissolution reaction rate was affected by both the chemical reaction on the surface and the diffusion throughout the product layer [16,17]. The reaction rate constants calculated from the model clearly showed that the dissolution rate of manganese increased with the increase in temperature. The reaction was approximately ten times faster when the temperature was raised from $25{ }^{\circ} \mathrm{C}$ to $95{ }^{\circ} \mathrm{C}$. In addition, the activation energy of manganese dissolution from $\mathrm{NaOH}$-MC treated laterite was calculated as 35.42 $\mathrm{kJ} / \mathrm{mol}$ based on the Arrhenius equation (Figure 7). Generally, it is known that the diffusion-controlled reaction has a typical activation energy of less than 20 $\mathrm{kJ} / \mathrm{mol}$ whereas it has over $40 \mathrm{~kJ} / \mathrm{mol}$ for the chemical controlled reaction [18]. The calculated activation value in this range confirmed the control mechanism. 


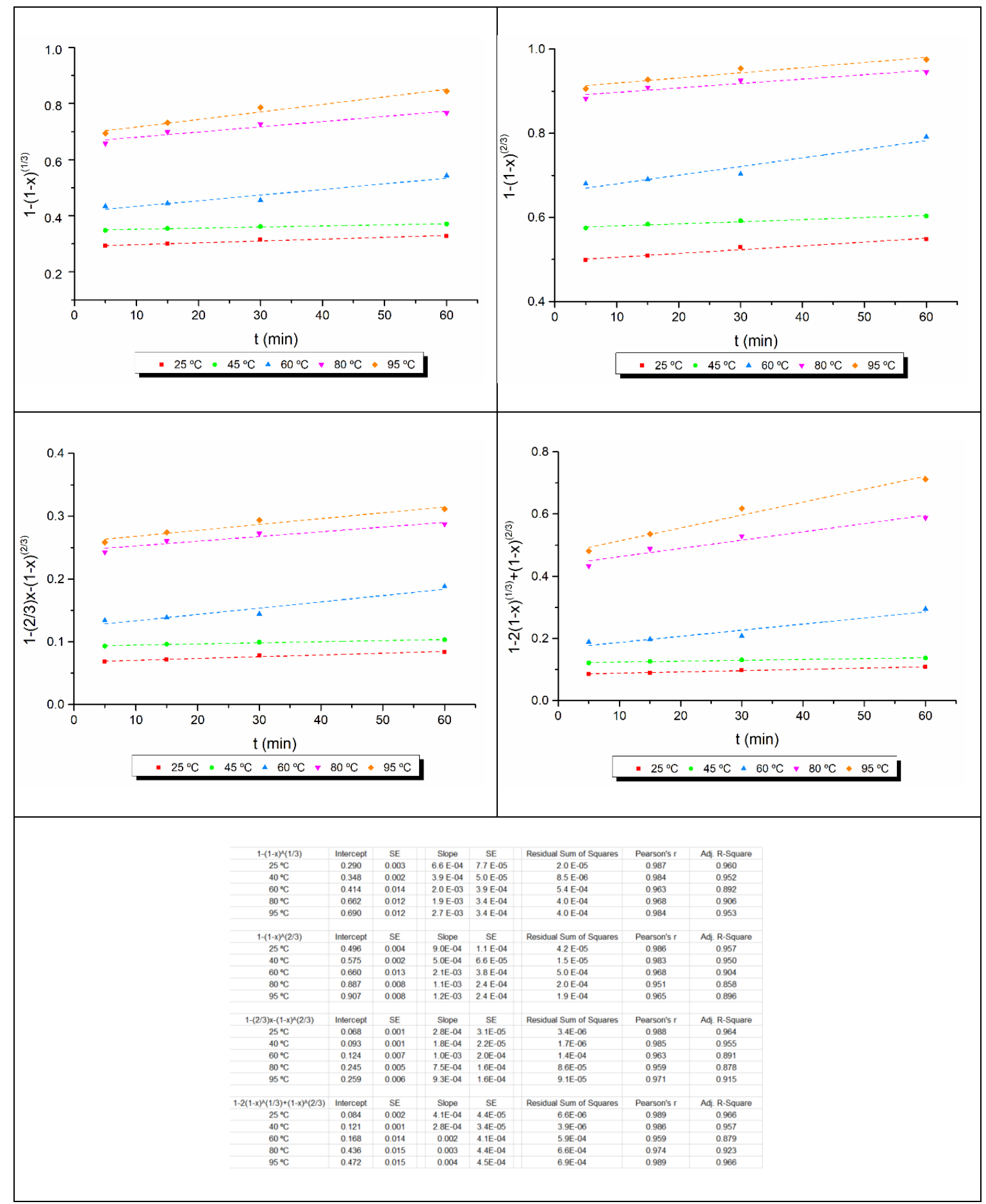

Figure 6. Fitting curves of SCM kinetic models 
Table 5. Correlation coefficients $\left(R^{2}\right)$ and reaction rate constants of the kinetic models in different temperatures for manganese dissolution

\begin{tabular}{|c|c|c|c|c|c|c|}
\hline \multirow{2}{*}{ Mechanisms of SCM } & \multirow{2}{*}{ Constants } & \multicolumn{5}{|c|}{$\mathrm{T}\left({ }^{\circ} \mathrm{C}\right)$} \\
\hline & & 25 & 40 & 60 & 80 & 95 \\
\hline \multirow{2}{*}{$\begin{array}{l}\text { Surface reaction } \\
1-(1-\alpha)^{1 / 3}\end{array}$} & $k_{\mathrm{s}}(1 / \mathrm{min})$ & 0.0007 & 0.0004 & 0.0020 & 0.0019 & 0.0027 \\
\hline & $\mathrm{R}^{2}$ & 0.96 & 0.95 & 0.89 & 0.91 & 0.95 \\
\hline \multirow{2}{*}{$\begin{array}{l}\text { Film diffusion } \\
1-(1-\alpha)^{2 / 3}\end{array}$} & $k_{\mathrm{f}}(1 / \mathrm{min})$ & 0.0009 & 0.0005 & 0.0021 & 0.0011 & 0.0012 \\
\hline & $\mathrm{R}^{2}$ & 0.96 & 0.95 & 0.90 & 0.86 & 0.90 \\
\hline \multirow{2}{*}{$\begin{array}{l}\text { Diffusion from product layer } \\
1-2 / 3 \alpha-(1-\alpha)^{2 / 3}\end{array}$} & $k_{\mathrm{d}}(1 / \min )$ & 0.0003 & 0.0002 & 0.0010 & 0.0008 & 0.0009 \\
\hline & $\mathrm{R}^{2}$ & 0.96 & 0.96 & 0.89 & 0.88 & 0.92 \\
\hline $\begin{array}{l}\text { Combination of chemical } \\
\text { reaction and diffusion }\end{array}$ & $k_{\mathrm{m}}(1 / \min )$ & 0.0004 & 0.0003 & 0.0020 & 0.0030 & 0.0040 \\
\hline $1-2(1-\alpha)^{1 / 3}+(1-\alpha)^{2 / 3}$ & $\mathrm{R}^{2}$ & 0.97 & 0.96 & 0.88 & 0.92 & 0.97 \\
\hline
\end{tabular}

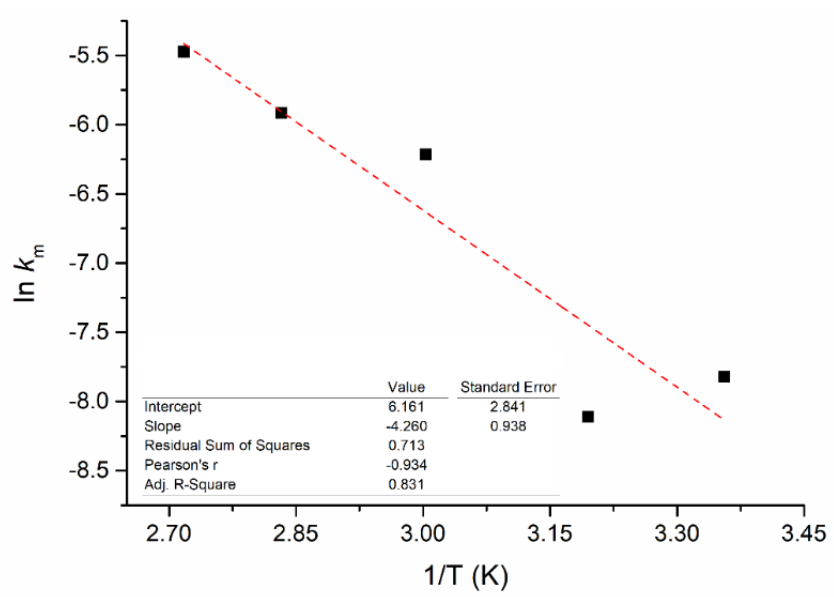

Figure 7. Determination of activation energy for manganese dissolution (Hold values: $\mathrm{Co}=0.5 \mathrm{M} \mathrm{H}_{2} \mathrm{SO}_{4}$ and L/S ratio $=55$ $\mathrm{mL} / \mathrm{g})$

\section{Conclusions}

In this study, the effect of the process developed to provide high-efficiency nickel recovery, which is a combination of a sodium-based reagent-assisted mechanochemical conversion and leaching, on the amount of manganese dissolved during nickel recovery was investigated. The results obtained from the studies were presented below:

- The optimum conditions of both $\mathrm{NaOH}$-MC and AL were determined by CCD and the manganese recovery was obtained over $95 \%$ with the proposed method.

- High determination coefficients above 95\% showed that RSM models can be used as a reliable method for predicting responses in both mechanochemical conversion and leaching processes conditions.

- Manganese recovery obtained from raw ore at 4 h leaching time $\left(3.08 \mathrm{M} \mathrm{H}_{2} \mathrm{SO}_{4}, 27.9 \mathrm{~mL} / \mathrm{g}\right.$ of
$\mathrm{L} / \mathrm{S}$ ratio, $95^{\circ} \mathrm{C}$ ) was achieved from $\mathrm{NaOH}-\mathrm{MC}$ treated laterite at only $30 \mathrm{~min}\left(0.50 \mathrm{M} \mathrm{H}_{2} \mathrm{SO}_{4}\right.$, $55 \mathrm{~mL} / \mathrm{g}$ of L/S ratio, $75^{\circ} \mathrm{C}$ ) following $\mathrm{NaOH}$ $\mathrm{MC}$. This is an obvious result of the positive effect of mechanochemical processes on the leachability of minerals.

- Moreover, the results indicated that the quantitative manganese recovery achieves with less acid consumption at lower temperatures and shorter times due to easier mass transfer. That is, $\mathrm{NaOH}$-MC processes contributed to the leachability of laterite by facilitating the dissolution reaction of both laterite and manganese as a result of caused deformations, phase transformations and increase of new reactive surfaces.

- The mineralogical and structural transformations occurring through as a result of mechanochemical processes identified by the characterization of $\mathrm{NaOH}$-MC treated laterites 
supported the positive effect of $\mathrm{NaOH}$-MC on the leachability of laterite ore and indirectly on the dissolution of manganese.

- The results of leaching kinetics evaluations indicated that the mechanism of manganese dissolution reaction rate for $\mathrm{AL}$ following $\mathrm{NaOH}-\mathrm{MC}$ was controlled by a combination of chemical and diffusion reactions based on SCM. Consequently, the results indicate that the proposed method for achieving high-efficiency nickel recovery can also improve the dissolution of manganese. The high amount of manganese above $95 \%$ achieved with less acid consumption at low temperatures and short times, due to the increased leachability of laterite.

\section{Acknowledgment}

This work was supported by the Scientific and Technological Research Council of Turkey (TÜBİTAK) [Grant Number 116M076].

\section{Conflicts of interest}

The authors state that did not have conflict of interests

\section{References}

[1] Xin B., Li T., Li X., Dan Z., Xu F., Duan N., Zhang $Y$. and Zhang $H$. Reductive dissolution of manganese from manganese dioxide ore by autotrophic mixed culture under aerobic conditions. J. Cleaner Prod., 92 (2015) 54-64.

[2] Zhang W., Cheng C.Y. and Pranolo Y. Investigation of methods for removal and recovery of manganese in hydrometallurgical processes. Hydrometallurgy, 101 (2010) 58-63.

[3] Zhang W., Cheng C.Y., Manganese metallurgy review. Part I: Leaching of ores/secondary materials and recovery of electrolytic/chemical manganese dioxide, Hydrometallurgy, 89 (2007) 137-159.

[4] Zhang Y., Chen X., Chu W., Cui H. and Wang M. Removal of vanadium from petroleum coke by microwave and ultrasonic-assisted leaching. Hydrometallurgy, 191, (2020) 105168.

[5] Li C., Liang B., Study on the mechanochemical oxidation of ilmenite, J. Alloys Compd., 459 (2008) 354-361.

[6] Baláž P., Mechanical activation in hydrometallurgy, Int. J. Miner. Process., 72 (2003) 341-354.

[7] Nayak A.K., Pal A., Statistical modeling and performance evaluation of biosorptive removal of Nile blue A by lignocellulosic agricultural waste under the application of high-strength dye concentrations. J. Environ. Chem. Eng., 8(2) (2020) 103677.

[8] Çetintaş S., Bingöl D., Response surface methodology approach to leaching of nickel laterite and evaluation of different analytical techniques used for the analysis of leached solutions, Anal. Methods., 8 (2016) 3075-3087.

[9] Abrouki Y., Anouzla A., Loukili H., Bennazha J., Lotfi R., Rayadh A., Bahlaoui M.A., Sebti, S., Zakarya D. and Zahouily M. Experimental designbased response surface methodology optimization for synthesis of $\beta$-mercapto carbonyl derivatives as antimycobacterial drugs catalyzed by calcium pyrophosphate. Int. J. Med. Chem., (2014) doi: http://dx.doi.org/10.1155/2014/586437.

[10] Montgomery D.C., Design and analysis of experiments, 7th ed. John Wiley \& Sons, New York, 2008.

[11] Lundstedt T., Seifert E., Abramo L., Thelin B., Nyström Å., Pettersen J., Bergman R. Experimental design and optimization. Chemometr. Intell. Lab. Syst., 42 (1998) 3-40.

[12] Çetintaş S., Yildiz U. and Bingöl D. A novel reagent-assisted mechanochemical method for nickel recovery from lateritic ore. J. Cleaner Prod., 199 (2018) 616-632.

[13] MacCarthy J., Nosrati A., Skinner W. and AddaiMensah J. Atmospheric acid leaching mechanisms and kinetics and rheological studies of a low grade saprolitic nickel laterite ore. Hydrometallurgy, 160 (2016) 26-37.

[14] Dehghan R., Noaparast M. and Kolahdoozan M. Leaching and kinetic modelling of low-grade calcareous sphalerite in acidic ferric chloride solution. Hydrometallurgy, 96(4) (2009) 275-282.

[15] Tunç T., Yıldız K., Effects of ball-to-mass ratio during mechanical activation on the structure and thermal behavior of Turkish lateritic nickel ore, TOJSAT., 3 (2013) 80-85.

[16] Ayanda O.S., Adekola F.A., Baba A.A., Fatoki O.S. and Ximba B.J. Comparative study of the kinetics of dissolution of laterite in some acidic media. JMMCE., 15 (2011) 1457-1472.

[17] Petrovski A., Načevski G., Dimitrov A.T. and Paunović P. Kinetic models of nickel laterite ore process. Inter. Sci. J. Mach. Technol. Mater., 13 (2019) 487-490.

[18] Liu K., Chen Q., Yin Z., Hu H. and Ding Z. Kinetics of leaching of a Chinese laterite containing maghemite and magnetite in sulfuric acid solutions. Hydrometallurgy, 125 (2012) 125136. 